\title{
Neuronal calcium sensor proteins - recognizing a face in a crowd
}

\author{
Robert H. Kretsinger* \\ University of Virginia, Charlottesville, VA, USA \\ *Correspondence: rhk5i@virginia.edu
}

\section{A commentary on}

Molecular structure and target recognition of neuronal calcium sensor proteins by Ames, J. B., Lim, S., and Ikura, M. (2012). Front. Mol. Neurosci. 5:10. doi: 10.3389/ fnmol.2012.00010

Ames, Lin, and Ikura in "Molecular structures and target recognition of neuronal calcium sensor proteins" describe the wide range of functions performed by the neuronal calcium sensor proteins in various nervous tissues. These NCS proteins are closely related in amino acid sequence and comprise 1 of over 70 subfamilies of proteins that contain 2-12 EF-hands. The N-termini of the NCS's are myristoylated and in their apo-forms this hydrophobic tail is discretely tucked into a cavity that differs among recoverin, NCS1, and GCAP1 - all of whose solutions structures have been determined by nuclear magnetic resonance spectroscopy. Ames et al. conclude that " $\mathrm{Ca}^{2+}$ induced extrusion of the myristoyl group exposes unique hydrophobic binding sites in each protein that in turn interact with distinct target proteins."

The calci-structures of seven NCS's, two with peptides from their respective targets bound, clearly revealed that the calci-structures differ significantly from one another and from their respective apo-structures. Therein lie their specificities for diverse targets within various cells of the nervous system. The EF-hands 1, 2 and EF-hands 3, 4 retain their approximate canonical shapes and relationships; however, the binding cavities between the two pairs of EF-hands vary to suit their chosen targets. These NCS structures reveal how small differences in amino sequences of close homologs can be amplified to major changes in cell function.

Received: 02 March 2012; accepted: 18 March 2012; published online: 02 April 2012.

Citation: Kretsinger RH (2012) Neuronal calcium sensor proteins - recognizing a face in a crowd. Front. Mol. Neurosci. 5:41. doi: 10.3389/fnmol.2012.00041

Copyright (c) 2012 Kretsinger. This is an open-access article distributed under the terms of the Creative Commons Attribution Non Commercial License, which permits noncommercial use, distribution, and reproduction in other forums, provided the original authors and source are credited. 